\title{
Pelatihan Penggunaan Aplikasi Kahoot untuk Pembelajaran Matematika secara Daring di SMK Nahdlatul Ulama Medan
}

\author{
Rani Rahim*1, Rizka Fahruza Siregar², Rini Ramadhani3
}

\author{
${ }^{1}$ Prodi Manajemen, Fakultas Ekonomi dan Bisnis, Universitas Dharmawangsa, Medan, Indonesia \\ ${ }^{2}$ Prodi Teknik Sipil, Fakultas Teknik, Universitas Pembinaan Masyarakat Indonesia, Medan, Indonesia \\ 3Prodi Teknik Mesin, Fakultas Teknik, Universitas Pembinaan Masyarakat Indonesia, Medan, Indonesia \\ *e-mail: ranirahim@dharmawangsa.ac.id ${ }^{1}$, rizkafahruza.siregar@gmail.com² ${ }^{2}$, \\ riniramadhani0901@gmail.com ${ }^{3}$
}

\begin{abstract}
Abstrak
Pada masa pandemi COVID-19, pembelajaran yang biasanya dilakukan secara tatap muka di kelas diganti dengan pembelajaran secara daring. Untuk mendukung agar pembelajaran dapat terlaksana dengan baik maka dibutuhkan suatu aplikasi yang dapat menunjang pembelajaran sehingga siswa lebih tertarik belajar daring selama di rumah. Kegiatan ini dilakukan secara terbatas dengan memberikan pelatihan kepada siswa mengenai penggunaan aplikasi Kahoot dalam pembelajaran matematika. Peserta dalam kegiatan ini adalah siswa/i kelas X SMK Nahdlatul Ulama Medan Tahun Ajaran 2020/2021. Metode yang digunakan dalam kegiatan ini adalah sosialisasi kemudian dilakukan pelatihan dan diakhiri dengan evaluasi penggunaan aplikasi Kahoot. Hasil dari kegiatan pengabdian ini adalah siswa dapat menggunakan aplikasi Kahoot dalam menjawab soal-soal yang diberikan guru selama pembelajaran daring. Sehingga dengan seperti itu siswa lebih tertarik untuk belajar matematika apalagi soal yang diberikan dalam aplikasi Kahoot adalah soal-soal kontekstual yang berhubungan dengan kehidupan sehari-hari siswa.
\end{abstract}

Kata kunci: Aplikasi Kahoot, Pelatihan, Pembelajaran Daring

\begin{abstract}
During the COVID-19 pandemic, learning that was usually done face-to-face in class was replaced with online learning. To support that learning can be carried out properly, an application that can support learning is needed so that students are more interested in learning online while at home. This activity was carried out in a limited manner by providing training to students on the use of the Kahoot application in learning mathematics. Participants in this activity were students of class X SMK Nahdlatul Ulama Medan for the 2020/2021 academic year. The method used in this activity is socialization, then training is carried out and ends with an evaluation of the use of the Kahoot application. The result of this service activity is that students can use the Kahoot application in answering questions given by the teacher during online learning. So that in this way students are more interested in learning mathematics, especially the questions given in the Kahoot application are contextual questions related to students' daily lives.
\end{abstract}

Keywords: Kahoot Application, Online Learning, Training

\section{PENDAHULUAN}

Pandemi COVID-19 mulai terjadi di Indonesia pada awal bulan Maret dan membuat segala sesuatu harus dikerjakan dari rumah (Work From Home atau yang biasa disingkat dengan WFH). Kebijakan tersebut dilakukan oleh Pemerintah demi terputusnya rantai penyebaran COVID-19. Pemerintah menganjurkan kepada masyarakat untuk semakin memiliki kesadaran pentingnya untuk stay at home, mencuci tangan dengan sabun, physical distancing (menjaga jarak), dan memakai masker jika keluar rumah. Kondisi seperti ini tentulah tidak mudah dihadapi, apalagi untuk orang-orang yang tidak terbiasa atau yang tidak bisa bekerja dari rumah. Selain itu dalam dunia pendidikan, Pemerintah juga telah menerapkan pembelajaran secara daring untuk siswa maupun mahasiswa. Selama pandemi ini, siswa maupun mahasiswa tidak belajar di sekolah ataupun kampus seperti biasa akan tetapi mereka melakukan proses pembelajaran dari rumah secara online atau daring. Pembelajaran seperti ini tidak semudah yang dibayangkan. Begitu banyak hal yang harus dipikirkan dan dipertimbangkan demi tercapainya tujuan pembelajaran yang harus dirancang sebelumnya, diantaranya strategi pembelajaran, metode, model, bahkan 
ketersediaan fasilitas yang menunjang dalam melakukan pembelajaran online atau daring tersebut.

Mengajar di masa pandemi seperti ini memang tidak mudah, namun di waktu yang seperti inilah orangtua dan guru seharusnya bisa bekerja sama untuk melakukan inovasi terbaru dalam pengajaran terhadap anak-anak mereka. Di masa seperti inilah peran guru dan orangtua sangat dibutuhkan oleh para siswa dalam belajar. Oleh karena itu, guru harus dapat merancang suatu media pembelajaran yang menarik agar pembelajaran secara daring lebih menyenangkan bagi siswa.

Kompetensi dan kemampuan tenaga pendidik untuk berinovasi dan tetap bertanggung jawab menjalankan tugas sebagai guru juga menjadi komponen penting yang mampu menciptakan proses pembelajaran yang efektif. Kita tidak bisa menyalahkan keadaan atau bahkan berhenti dan menyerah karena keadaan. Apapun yang terjadi, pendidikan akan terus berjalan. Oleh karena itu, dibutuhkan kerjasama antara guru sebagai tenaga pendidik dan siswa sebagai anak didik untuk dapat menciptakan proses pembelajaran yang efektif, menarik, dan inovatif sehingga mampu mencapai tujuan pembelajaran.

Berdasarkan wawancara yang telah dilakukan kepada salah satu guru di SMK Nahdlatul Ulama Medan mengatakan bahwa sulitnya siswa belajar secara daring apalagi selama pandemi ini, beberapa guru hanya menggunakan WhatsApp (WA) grup saja dalam menyampaikan materi kepada siswa. Hal tersebut menyebabkan siswa merasa pembelajaran daring kurang efektif atau tidak menyenangkan. Apalagi sulitnya siswa dalam belajar matematika yang dilakukan secara daring. Selama ini, matematika adalah salah satu mata pelajaran yang dianggap paling sulit bagi siswa. Hal ini dikarenakan, guru hanya mengajarkan konsep materi secara langsung kepada siswa. Guru jarang memberikan masalah terlebih dahulu dan tidak mengaitkan konsep tersebut ke dalam kehidupan sehari-hari. Dengan begitu, siswa kurang bersemangat untuk belajar matematika. Oleh karena itu, sangat penting bagi guru untuk mengembangkan sebuah media pembelajaran yang dapat mendukung pembelajaran daring agar lebih efektif dan menarik.

Konsep dalam kegiatan pengabdian ini adalah mengacu pada game based learning yang merupakan teknik pembelajaran berlandaskan permainan yang dapat membantu meningkatkan potensi dan kualitas pelajar dalam menyerap pengetahuan. Pembelajaran berlandaskan permainan merupakan alat yang dapat membantu siswa dalam menyelesaikan masalah, meningkatkan pemikiran kritis dan membuat sebuah penilaian dalam proses pembelajaran (Dellos, 2015). Penelitian pada bidang desain pendidikan telah menunjukkan bahwa game based learning atau pembelajaran berbasis permainan adalah salah satu alat yang efektif dalam pengajaran terutama untuk menjaga motivasi keberlanjutan belajar (Huang, 2011).

Dewasa ini untuk menciptakan pembelajaran yang menarik membutuhkan media teknologi sebagai perantara interaksi dalam proses pembelajaran. Pembelajaran merupakan proses interaksi komunikasi antara sumber belajar, guru dan siswa (Rusman, 2013). Pemanfaatan teknologi sebagai media pembelajaran untuk mempermudah baik bagi guru maupun siswa dalam mengelola, menyampaikan informasi serta menjadikan pengalaman belajar yang berbeda (Nurseto, 2012). Pemanfaatan media dalam pembelajaran dapat membangkitkan keinginan dan minat baru, meningkatkan motivasi dan rangsangan kegiatan belajar, dan bahkan berpengaruh secara psikologis kepada siswa (Hamalik, 2008).

Salah satu media yang cocok digunakan oleh guru dalam pembelajaran secara daring adalah media pembelajaran aplikasi Kahoot. Diharapkan dengan aplikasi Kahoot ini, pembelajaran menjadi interaktif dan menarik serta dapat membantu guru dalam membuat evaluasi penilaian terhadap siswa. Aplikasi Kahoot dapat mempermudah guru dalam mengevaluasi (Afrianto, 2018). Kahoot merupakan salah satu alternatif pilihan dari berbagai macam media pembelajaran interaktif yang menjadikan proses pembelajaran menjadi menyenangkan dan tidak membosankan baik bagi siswa maupun bagi guru karena aplikasi Kahoot menekankan gaya belajar yang melibatkan hubungan peran aktif partisipasi siswa dengan rekan-rekan sejawatnya secara kompetitif terhadap pembelajaran yang sedang atau telah dipelajarinya (Harlina binti Ishak, 2017). Kahoot dapat mempengaruhi perkembangan sosial emosional anak dalam kemampuan berkompetisi dan berkolaborasi (Fitri R \& Anisa Y. S, 2017).

Pembelajaran menggunakan Aplikasi Kahoot membutuhkan piranti jaringan internet, 
komputer, infocus dan telepon pintar (smartphone). Pembelajaran dengan komputer dapat merangsang siswa untuk mengerjakan berbagai latihan dikarenakan tersedianya berbagai animasi, ilustrasi grafik, dan warna yang menambah realisme (Azhar, 2008).

Dikarenakan permasalahan yang telah ditemukan di sekolah tersebut dan dari hasil observasi serta wawancara yang dilakukan kepada salah satu guru matematika maka tim pengabdi tertarik melakukan pengabdian di sekolah tersebut dan melakukan sosialisasi aplikasi ke siswa kelas X. Pengabdi memilih kelas X dikarenakan siswa di kelas X adalah siswa yang dari awal sudah melakukan pembelajaran secara daring. Sehingga diharapkan dengan sosialisasi tersebut siswa mendapatkan pengetahuan tentang aplikasi Kahoot.

Tujuan dari pengabdian ini adalah agar siswa dapat menggunakan aplikasi Kahoot dalam pembelajaran matematika serta dapat meningkatkan motivasi belajar matematika siswa selama pembelajaran daring di rumah.

\section{METODE}

Khalayak sasaran dalam kegiatan pengabdian kepada masyarakat ini adalah siswa/i kelas X SMK Nahdlatul Ulama Medan Tahun Ajaran 2020/2021 yang terdiri dari 30 siswa. Metode yang digunakan dalam kegiatan ini adalah sosialisasi, pelatihan serta evaluasi penggunaan aplikasi Kahoot dalam pembelajaran matematika. Kegiatan ini dilakukan di SMK Nahdlatul Ulama Medan pada tanggal 9 September 2020.

Tahapan kegiatan yang dilakukan adalah :

a. Mengumpulkan informasi mengenai metode pembelajaran yang dilakukan oleh guru serta kendala yang dialami siswa dalam pembelajaran matematika selama belajar daring di rumah.

b. Sosialisasi mengenai aplikasi Kahoot kepada siswa secara langsung.

c. Pelatihan menggunakan aplikasi Kahoot dalam pembelajaran.

d. Evaluasi mengenai penggunaan aplikasi Kahoot dengan cara memberikan kuesioner kepada siswa.

\section{HASIL DAN PEMBAHASAN}

Kegiatan pengabdian kepada masyarakat dilakukan kepada siswa/i kelas X SMK Nahdlatul Ulama Medan Tahun Ajaran 2020/2021. Dalam kegiatan tersebut dilakukan sosialisasi kemudian dilakukan pelatihan dan diakhiri dengan evaluasi penggunaan aplikasi Kahoot. Berikut ini adalah tahapan kegiatan yang dilakukan oleh tim pengabdi selama di SMK Nahdlatul Ulama Medan :

\subsection{Mengumpulkan Informasi Mengenai Metode Pembelajaran}

Ketika pertama kali berkunjung ke SMK Nahdlatul Ulama, maka tim pengabdi melakukan kunjungan awal di sekolah tersebut dengan mengobservasi serta mewawancarai beberapa guru untuk bertanya mengenai metode pembelajaran apa yang dilakukan oleh guru selama pembelajaran daring. Setelah melakukan wawancara maka diperoleh hasil wawancara adalah guru hanya menggunakan WhatsApp (WA) grup saja dalam menyampaikan materi kepada siswa. Hal tersebut menyebabkan siswa merasa pembelajaran daring kurang efektif atau tidak menyenangkan. Apalagi sulitnya siswa dalam belajar matematika yang dilakukan secara daring.

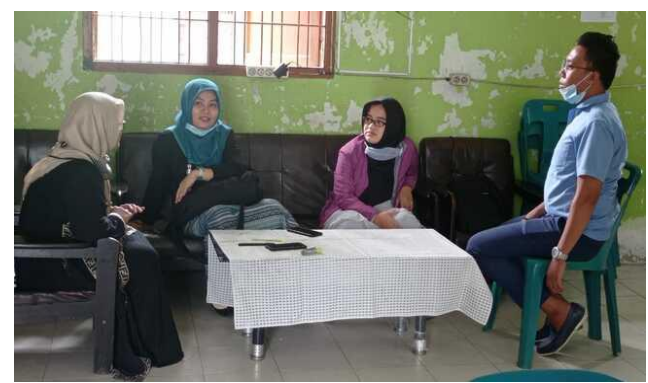

Gambar 1. Observasi Awal 


\subsection{Sosialisasi Mengenai Aplikasi Kahoot Kepada Siswa Secara Langsung}

Tim pengabdi melakukan sosialisasi dengan memberikan informasi mengenai aplikasi Kahoot serta penggunaannya dalam proses pembelajaran daring. Sosialisasi ini dilakukan secara langsung dan sebagai tahap awal pengenalan aplikasi Kahoot kepada siswa. Hal ini dikarenakan agar siswa lebih paham dan mengetahui aplikasi Kahoot dan penggunaannya dalam pembelajaran matematika.

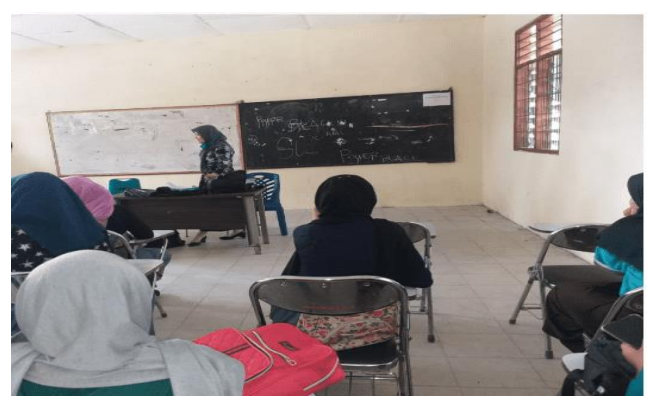

Gambar 2. Suasana Pelatihan Penggunaan Aplikasi Kahoot Secara Langsung

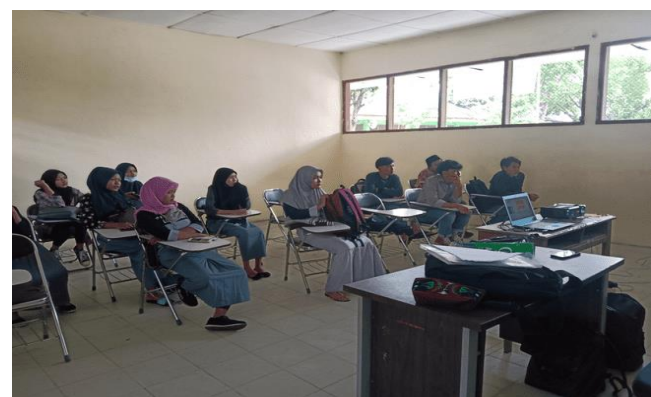

Gambar 3. Siswa Sedang Mendengarkan Penjelasan Dari Tim Pengabdi Mengenai Penggunaan Aplikasi Kahoot

\subsection{Pelatihan Menggunakan Aplikasi Kahoot Dalam Pembelajaran}

Setelah tim pengabdi melakukan sosialisasi secara langsung kepada siswa mengenai penggunaan aplikasi Kahoot, maka selanjutnya siswa mencoba sendiri aplikasi Kahoot tersebut dari handphone mereka masing-masing. Tim pengabdi memberikan link kepada siswa agar siswa dapat membuka aplikasi Kahoot di handphone masing-masing dan dapat menjawab soal yang ada di aplikasi tersebut. Tim pengabdi menyuruh siswa untuk menjawab soal yang ada di aplikasi Kahoot tersebut dengan durasi waktu 5 menit untuk setiap soal. Soal yang diberikan sebanyak 10 soal. Siswa yang memiliki skor yang tertinggi maka akan mendapatkan hadiah.

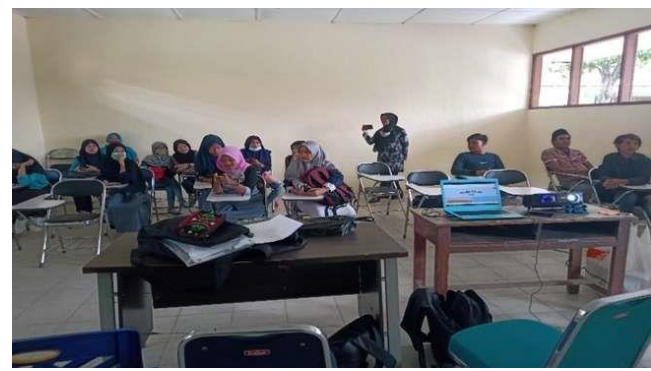

Gambar 4. Siswa Menjawab Soal Yang Diberikan Oleh Tim Pengabdi Dengan Menggunakan Aplikasi Kahoot

Setelah semua soal sudah dijawab oleh siswa maka dari hasil jawaban siswa dan waktu pengerjaan yang dilakukan semua siswa dapat dilihat secara keseluruhan. Sehingga dari hasil tersebut, maka tim pengabdi memberikan hadiah kepada salah seorang siswa sebagai rewards karena memiliki skor tertinggi diantara teman yang lainnya. 


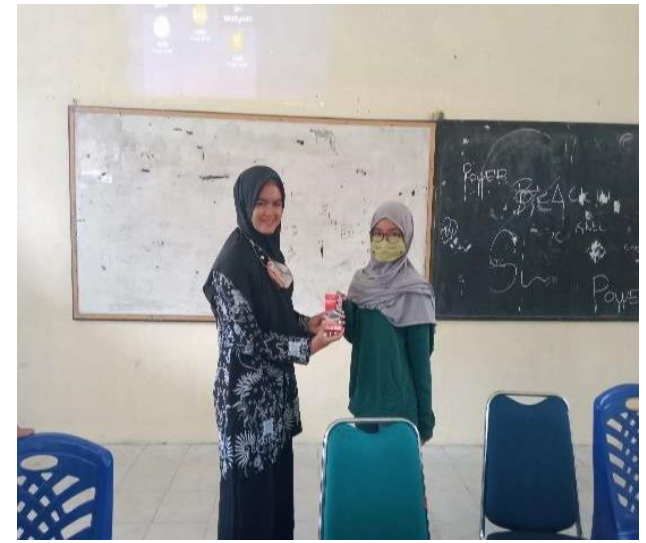

Gambar 5. Tim Pengabdi Memberikan Hadiah Kepada Salah Satu Siswa Sebagai Rewards

\subsection{Evaluasi Mengenai Penggunaan Aplikasi Kahoot Dengan Cara Memberikan Kuesioner Kepada Siswa}

Setelah dilakukan sosialisasi dan pelatihan penggunaan aplikasi Kahoot kepada siswa, maka selanjutnya dilakukan evaluasi mengenai penggunaan aplikasi Kahoot dengan cara memberikan kuesioner kepada siswa. Kuesioner yang diberikan berbentuk link google form. Pengisian kuesioner dilakukan untuk memberikan penilaian mengenai penggunaan aplikasi Kahoot dalam pembelajaran matematika. Kuesioner diiisi oleh siswa melalui handphone masingmasing. Berikut ini adalah hasil dari kuesioner yang telah diisi oleh siswa:

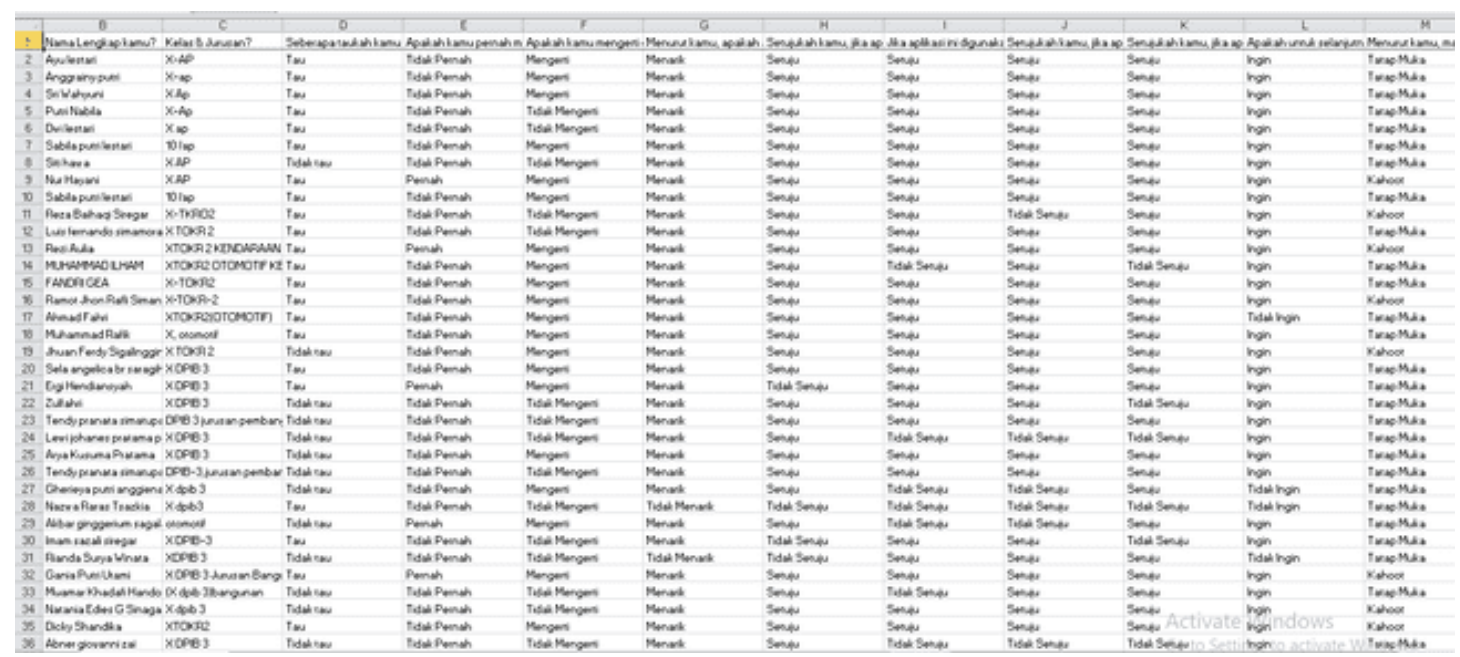

Gambar 6. Hasil Kuesioner Yang Telah Diisi Oleh Siswa Melalui Google Form

Setelah sosialisasi, pelatihan serta evaluasi kepada siswa dalam penggunaan aplikasi Kahoot maka selanjutnya tim pengabdi melakukan sesi foto dengan siswa serta guru mata pelajaran di sekolah tersebut.

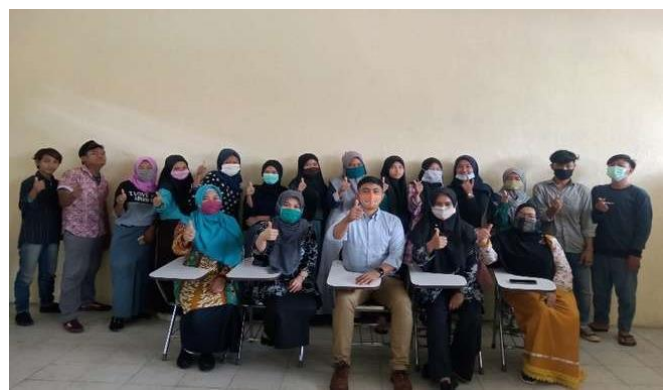

Gambar 7. Foto Tim Pengabdi Bersama Dengan Guru-Guru Serta Siswa/I SMK Nahdlatul Ulama Medan 


\subsection{Hasil Pengabdian} dilakukan:

Berikut ini adalah penjelasan perbedaan sebelum dan sesudah kegiatan pengabdian

Tabel 1. Hasil Pengabdian

\begin{tabular}{|c|c|c|c|}
\hline No & Jenis Kegiatan & Kegiatan Sebelum Pengabdian & Kegiatan Setelah Pengabdian \\
\hline 1. & Observasi Awal & $\begin{array}{l}\text { Selama pembelajaran daring, guru } \\
\text { hanya menggunakan WhatsApp } \\
\text { (WA) grup saja dalam } \\
\text { menyampaikan materi } \\
\text { siswa. }\end{array}$ & $\begin{array}{l}\text { Siswa menggunakan aplikasi } \\
\text { Kahoot dalam menjawab soal yang } \\
\text { diberikan oleh guru. }\end{array}$ \\
\hline 2. & Sosialisasi & $\begin{array}{l}\text { Siswa belum pernah mengetahui } \\
\text { tentang aplikasi Kahoot. }\end{array}$ & $\begin{array}{l}\text { Siswa sudah mengetahui aplikasi } \\
\text { Kahoot dan cara } \\
\text { menggunakannya. }\end{array}$ \\
\hline 3. & Pelatihan & $\begin{array}{l}\text { Siswa tidak pernah menggunakan } \\
\text { aplikasi Kahoot dalam } \\
\text { pembelajaran. }\end{array}$ & $\begin{array}{l}\text { Siswa sudah menggunakan } \\
\text { aplikasi } \\
\text { pembelajaran. }\end{array}$ \\
\hline 4. & Evaluasi & $\begin{array}{l}\text { Menggunakan WhatsApp (WA) } \\
\text { grup dalam pembelajaran. }\end{array}$ & $\begin{array}{l}\text { Siswa sudah menggunakan } \\
\text { aplikasi Kahoot dan memberikan } \\
\text { penilaian mengenai aplikasi } \\
\text { tersebut dengan mengisi link } \\
\text { google form yang diberikan oleh } \\
\text { tim pengabdi kepada siswa. }\end{array}$ \\
\hline
\end{tabular}

Selama pelaksanaan kegiatan pengabdian kepada masyarakat tidak ditemukan kesulitan atau hambatan. Hal ini mengakibatkan kegiatan pengabdian kepada masyarakat berjalan dengan lancar serta sesuai dengan yang diharapkan. Selain itu, dapat diperoleh hasil dari kegiatan pengabdian kepada masyarakat oleh tim pengabdi di SMK Nahdlatul Ulama Medan adalah sebagai berikut:

Tabel 2. Respon Siswa dalam Menggunakan Aplikasi Kahoot

\begin{tabular}{|c|c|c|c|c|}
\hline \multirow{2}{*}{$\begin{array}{c}\text { No. } \\
1 .\end{array}$} & \multirow{3}{*}{$\begin{array}{c}\text { Aspek yang diamati } \\
\text { Seberapa taukah kamu dengan }\end{array}$} & \multicolumn{2}{|c|}{ Respon } & \multirow{2}{*}{$\frac{\text { Persentase }}{33 \%}$} \\
\hline & & Tau & 10 siswa & \\
\hline & & Tidak Tau & 20 siswa & $67 \%$ \\
\hline \multirow[t]{2}{*}{2.} & \multirow{2}{*}{$\begin{array}{l}\text { Apakah kamu pernah menggunakan } \\
\text { aplikasi ini sebelumnya? }\end{array}$} & Pernah & 5 siswa & $17 \%$ \\
\hline & & Tidak Pernah & 25 siswa & $83 \%$ \\
\hline \multirow[t]{2}{*}{3.} & \multirow{2}{*}{$\begin{array}{l}\text { Apakah kamu mengerti dalam } \\
\text { menggunakan aplikasi ini? }\end{array}$} & Mengerti & 20 siswa & $67 \%$ \\
\hline & & Tidak Mengerti & 10 siswa & $33 \%$ \\
\hline \multirow[t]{2}{*}{4.} & \multirow{2}{*}{$\begin{array}{l}\text { Menurut kamu, apakah aplikasi ini } \\
\text { menarik jika digunakan untuk media } \\
\text { pembelajaran? }\end{array}$} & Menarik & 27 siswa & $90 \%$ \\
\hline & & Tidak Menarik & 3 siswa & $10 \%$ \\
\hline \multirow[t]{2}{*}{5.} & \multirow{2}{*}{$\begin{array}{l}\text { Setujukah kamu, jika aplikasi ini } \\
\text { digunakan pada pembelajaran daring } \\
\text { pada masa pandemi seperti ini? }\end{array}$} & Setuju & 25 siswa & $83 \%$ \\
\hline & & Tidak Setuju & 5 siswa & $17 \%$ \\
\hline \multirow[t]{2}{*}{6.} & \multirow{2}{*}{$\begin{array}{l}\text { Jika aplikasi ini digunakan kembali } \\
\text { pada saat pembelajaran matematika } \\
\text { di dalam kelas, apakah kamu setuju? }\end{array}$} & Setuju & 22 siswa & $73 \%$ \\
\hline & & Tidak Setuju & 8 siswa & $27 \%$ \\
\hline \multirow[t]{2}{*}{7.} & \multirow{2}{*}{$\begin{array}{l}\text { Setujukah kamu, jika aplikasi ini } \\
\text { membuat siswa menjadi suka untuk } \\
\text { belajar matematika? }\end{array}$} & Setuju & 24 siswa & $80 \%$ \\
\hline & & Tidak Setuju & 6 siswa & $20 \%$ \\
\hline \multirow[t]{2}{*}{8.} & \multirow{2}{*}{$\begin{array}{l}\text { Setujukah kamu, jika aplikasi ini } \\
\text { dapat membuat hasil belajar } \\
\text { matematika siswa meningkat? }\end{array}$} & Setuju & 24 siswa & $80 \%$ \\
\hline & & Tidak Setuju & 6 siswa & $20 \%$ \\
\hline
\end{tabular}


9. Apakah untuk selanjutnya kamu ingin mendalami tentang aplikasi Kahoot terutama dalam mata pelajaran matematika?

10. Menurut kamu, mana yang lebih menarik jika pembelajaran dilakukan melalui media aplikasi Kahoot atau

$\begin{array}{ccc}\text { Ingin } & 25 \text { siswa } & 83 \% \\ \text { Tidak Ingin } & 5 \text { siswa } & 17 \% \\ & & \\ \text { Tatap Muka } & 9 \text { siswa } & 30 \% \\ \text { Kahoot } & 21 \text { siswa } & 70 \% \\ & & \\ & & \end{array}$

Dari tabel di atas, maka dapat disimpulkan bahwa siswa lebih tertarik menggunakan aplikasi Kahoot dalam pembelajaran matematika.

\section{KESIMPULAN}

Kegiatan pengabdian kepada masyarakat yang telah dilakukan di SMK Nahdlatul Ulama Medan memberikan pengetahuan kepada siswa mengenai aplikasi Kahoot dan siswa lebih tertarik menggunakan aplikasi Kahoot dalam pembelajaran matematika. Hal ini dikarenakan semangat belajar siswa lebih meningkat dibandingkan dengan metode pembelajaran yang biasa digunakan mereka. Saran untuk kegiatan pengabdian selanjutnya adalah menerapkan penggunaan aplikasi yang lain dalam pembelajaran matematika yang dapat meningkatkan motivasi belajar siswa seperti aplikasi Quizizz, dll.

\section{DAFTAR PUSTAKA}

Afrianto, H. (2018). Pengembangan Alat Evaluasi Menggunakan Aplikasi Kahoot Pada Pembelajaran Matematika Kelas X. Journal of Linguistics, 3(2), 139-157.

Azhar, A. (2008). Media Pembelajaran. Jakarta: Raja Grafindo Persada.

Dellos, R. (2015). Kahoot! A digital game resource for learning. International Journal of Instructional Technology and Distance Learning, 12(4), 53-56.

Fitri R, \& Anisa Y. S. (2017). TIK UNTUK AUD: Penggunaan Platform "Kahoot" dalam Menumbuhkan Jiwa Kompetetif dan Kolaboratif Anak. PEDAGOGI: Jurnal Anak Usia Dini Dan Pendidikan Anak Usia Dini, 3(3), 164-172.

Hamalik, O. (2008). Perencanaan Pengajaran Berdasarkan Pendekatan Sistem. Jakarta : Dinamika Ilmu.

Harlina binti Ishak, Z. M. N. \& A. A. (2017). Pembelajaran Interaktif Berasaskan Aplikasi Kahoot dalam Pengajaran Abad Ke-21. Prosiding Seminar Serantau Ke-8 2017, 627-635.

Huang, W. H. (2011). Evaluating learners' motivational and cognitive processing in an online game-based learning environment. Computers in Human Behavior, 27(2), 694-704. https://doi.org/10.1016/j.chb.2010.07.021

Nurseto, T. (2012). Membuat Media Pembelajaran yang Menarik. Jurnal Ekonomi Dan Pendidikan, 9(1), 19-35. https://doi.org/10.21831/jep.v8i1.706

Rusman, D. (2013). Pembelajaran Berbasis Tekhnologi Informasi Dan Komunikasi. Depok: Rajawali Pers. 


\section{Halaman Ini Dikosongkan}

